\title{
Curcumae Ameliorates Diethylnitrosamine-Induced Hepatocellular Carcinoma via Alteration of Oxidative Stress, Inflammation and Gut Microbiota
}

\author{
Yunyan Zhang' \\ Xuelian $\mathrm{Li}^{2}$ \\ Xinghua $\mathrm{Li}\left(\mathbb{D}^{3}\right.$ \\ 'Department of Laboratory Medicine, \\ The First People's Hospital of \\ Lianyungang City, Lianyungang City, \\ Jiangsu, 222002, People's Republic of \\ China; ${ }^{2}$ Department of Laboratory \\ Medicine, The Fourth People's Hospital \\ of Lianyungang City, Lianyungang City, \\ Jiangsu, 222002, People's Republic of \\ China; ${ }^{3}$ Department of Blood \\ Transfusion, The First People's Hospital \\ of Lianyungang City, Lianyungang City, \\ Jiangsu, 222002, People's Republic of \\ China
}

Background: Nonalcoholic fatty liver disease (NAFLD) increased the risk factor of hepatocellular carcinoma (HCC). NAFLD induces the hepatic-related cancer deaths mostly in middle-aged men. NAFLD enhanced the inflammatory reaction and oxidative stress in the hepatic tissue. Curcumae exhibited the anti-inflammatory and antioxidant effects. In this study, we made an attempt to scrutinize the protective effect of curcumae on obesity-induced HCC via alteration of inflammation, oxidative stress and gut microbiota.

Methods: The rats used in this experiment were Wistar rats, $100 \mathrm{mg} / \mathrm{kg}$ intraperitoneal injection of diethylnitrosamine (hepatic carcinogen) was used at 2 weeks. After 6 weeks of the experimental study, the rats were randomly divided into high-fat diet (HFD) with or without curcumae-treated group rats and received the treatment for 22 weeks. Hepatic, nonhepatic, cardiac, antioxidant, pro-inflammatory and inflammatory were estimated at the end of the study. The stools of the experimental rats were collected for estimating the gut microbiota.

Results: Curcumae-treated group rats exposed reduction of the hepatic nodules in hepatic tissue. Curcumae significantly $(\mathrm{P}<0.001)$ diminished the level of hepatic parameters and antioxidant parameters in the serum. Curcumae significantly $(\mathrm{P}<0.001)$ suppressed the proinflammatory cytokines level, viz. interleukin-1 $\beta$ (IL-1 $\beta$ ), interleukin-6 (IL-6), tumor necrosis factor- $\alpha$ (TNF- $\alpha$ ), interleukin-2 (IL-2), interleukin-7 (IL-7) and augmented the level of interleukin-10 (IL-10) in the serum and hepatic tissue. Curcumae significantly $(\mathrm{P}<0.001)$ suppressed inflammatory mediators including cyclooxygenase (COX-2), prostaglandin E2 (PGE2) and nuclear factor kappa $\mathrm{B}(\mathrm{NF}-\mathrm{\kappa B})$ in the serum and hepatic tissue. Furthermore, curcumae increased the gut microbial diversity and richness and decreased the relative abundance of genus Mucispirillum and Clostridium, respectively.

Conclusion: Curcumae prevents HFD-induced inflammation during the hepatic carcinoma by modulating the oxidative stress, inflammatory reaction and gut microbiota.

Keywords: curcumae, hepatic cellular carcinoma, gut microbiota, inflammation, antioxidant

\section{Introduction}

NAFLD commonly affects the vital organ such as hepatic tissue. In China, NAFLD is a common disease that affects women, men, children and older people. ${ }^{1}$ According to the reports, $3 \%$ cases of NAFLD can boost during the inflammatory stage, which can further induce liver cirrhosis and finally cause liver failure and end-stage liver disease including hepatocellular carcinoma (primary liver cancer). ${ }^{1,2}$ At that time, only liver transplantation was the only option to treat the disease. Currently, both death rate and incidence of HCC are greater in China. In China, the incidence rate of HCC is 40 in
Correspondence: Xinghua Li

Department of Blood Transfusion, The First People's Hospital of Lianyungang

City, Lianyungang City, Jiangsu, 222002,

People's Republic of China

Email qwemn0|47@sina.com 
males and 15.3 in females per $1,00,000$ and the mortality rate 37.4 in males and 14.3 in females per 1,00,000, respectively. ${ }^{3}$ The incidence of NAFLD between normal and obese people has been reported to be $25 \%$ and $67.5 \%$, respectively. Furthermore, NAFLD has been related to changes in gut microbiota, plays a key role in the progression of a chronic low-grade inflammatory state in the host, and promotes the growth of NASH and HCC. ${ }^{1,2}$ Studies suggest that HCC patients suffering from NAFLD have more complex tumor and have shorter survival duration. Due to the high mortality rate and poor prognosis, no effective therapeutics were available for treating $\mathrm{HCC}$, which reduce the progression and expansion of $\mathrm{HCC}$, so it is necessary to scrutinize the potential chemotherapeutics for treating HCC. ${ }^{1,2,4}$

HCC is the world's fifth most common cancer, and it ranks third in terms of deaths among all cancers. ${ }^{5,6}$ It is well known that chronic inflammation induced by biological, physical factors and chemical is commonly observed in human cancers. Studies suggest that the primary liver cancer (70-90\%) is considered the HCC. ${ }^{7,8}$ Hepato-carcinogenesis is closely associated with liver cirrhosis, which grow after 20-40 years of chronic liver inflammation and finally cause the HCC. ${ }^{9}$ Currently available therapeutics such as transplantation, ablation and resection are available for treating the early stage of HCC. Sorafenib and chemoembolization for treating intermediate stage and end stage of HCC, respectively. ${ }^{10}$ The effect of the inflammation fibrosis cancer axis plays a role between inflammation and cancer. Moreover, it boosts the inflamed liver evolving to HCC and cirrhosis/fibrosis. ${ }^{8,11}$ Various risk factors, such as chemicals, toxicants, parasites, viruses and alcohol, induce inflammation, leading the chronic hepatic diseases, which may further expand the various stages of cirrhosis, fibrosis and HCC. ${ }^{11,12}$ $\mathrm{HCC}$ is the final stage of this process. Moreover, the various patients cannot be observed at an early stage, resultant delayed treatment; moreover, recurrence is of high frequency due to microscopic dissemination, which ultimately increases the survival rate of 5 years for HCC patients. ${ }^{13,14}$ Moreover, the prevention of HCC disease is at the primary stage to decrease the disease burden. Chemoprevention is an essential way to treat HCC. For treating HCC, the expansion of disease can be reversed or arrested in the early stage of carcinogenesis. ${ }^{5,15}$

Published literature suggests that traditional Chinese medicines contain various active phyto-constituents, which show a remarkable anticancer effect with or without inducing the little or no untoward effects. Curcumae (1,7-bis[4-hydroxy-3-methoxyphenyl]-1,6-heptadiene3,5-dione) is a hydrophobic polyphenol isolated from the turmeric (jiang huang) and widely used as flavoring and coloring agent in the food industry and also used as a active ingredients of various herbal formulation. ${ }^{16-18}$ Traditionally, curcumae has been used in various herbal formulations against the various diseases. Curcumae is the major phytoconstituent of jiang huang and it has demonstrated the antimicrobial, anticarcinogenic, antioxidant, antidiabetic and anti-inflammatory effects. The curcumae is used in herbal medicine for the treatment of various diseases such as diarrhea, vomiting, headache, etc. ${ }^{19,20}$ Currently, pharmacological investigations have demonstrated that curcumae has powerful antiinflammatory, anticancer, antioxidant and anti-microbial activities. ${ }^{19,20}$ Curcumae appears to be a very safe product for humans, according to growing research. It has the ability to not only prevent carcinogenesis and improve chemotherapy therapeutic efficacy by sensitising cancer cells to routinely used chemotherapy but also to protect normal cells from chemotherapy-induced damage. ${ }^{19}$ Curcumae exhibited a protective effect against the gut microbiota due to antioxidant, anti-inflammatory and gut-protective effect of curcumae. In the current experimental study, we scrutinized the chemoprotective effect of curcumae against the diethylnitrosamine (DEN)-induced and high-fat diet (HFD)-promoted HCC development in the rats. Additionally, we investigated the preventive effect of curcumae on the gut microbiome in the HFD-promoted hepatic cancer model.

\section{Materials and Methods Chemical}

Curcumae (98\%), diethylnitrosamine (DEN), dimethyl sulfoxide (DMSO) were purchased from Sigma-Aldrich (St. Louis, MO, USA). Dulbecco's Modified Eagle Medium (DMEM), fetal bovine serum (FBS), streptomycin and penicillin were purchased from the Invitrogen-Gibco (Grand Island, NY). Biochemical kits were purchased from the Nanjing Jiancheng Bioengineering Institute, China. All other chemicals were purchased from Sigma-Aldrich (St. Louis, MO, USA).

\section{Animals}

For this experiment, albino Wistar rats (weighing $125 \pm 20$ g) were used. The rats were brought from the departmental Animal House and were housed in polyethylene cages. 
The animals were acclimated to the normal conditions $\left(25^{\circ} \mathrm{C} ; 12 / 12 \mathrm{~h}\right.$ light and dark cycle). The rats were fed regular rat chow and free access to water. The whole animal study was approved from the Institute (3829-3432).

\section{Induction of Hepatocellular Carcinoma (HCC)}

For the induction of HCC, intraperitoneal injection of DEN (100 mg/kg, b.w.) was used. ${ }^{1}$ The rats were received an intraperitoneal injection of DEN on day 0. After the DEN was induced, alpha fetoprotein (AFP) was measured to confirm the existence of HCC.

\section{Experimental Procedure}

The rats were divided into five groups as follows: Group I: normal control (received PBS); Group II: DEN (100 mg/kg dissolved in PBS) + HFD; Group III: DEN (100 mg/kg) + HFD + Curcumae (2.5 mg/kg); Group IV: DEN $(100 \mathrm{mg} / \mathrm{kg})$ + HFD + Curcumae $(5 \mathrm{mg} / \mathrm{kg})$ and Group V: DEN $(100 \mathrm{mg} /$ $\mathrm{kg})+$ HFD + Curcumae $(10 \mathrm{mg} / \mathrm{kg})$ for 22 weeks.

The body weight, water and food intake of all groups were estimated at a regular interval. Blood samples were collected from all groups of rats were obtained by puncturing the heart at the end of the study, and all groups of rats were scarified by cervical dislocation. The blood samples of all groups were kept at $4{ }^{\circ} \mathrm{C}$ and centrifuged for separation of the plasma for further biochemical and other parameters' estimation.

\section{Biochemical Parameters}

At the end of the study, all groups of rats were used for estimating biochemical parameters such as alkaline phosphatase (ALP) (A059-1-1), alpha fetoprotein (AFP) (E014-1-1), aspartate transaminase (AST) (C010-2-1), alanine transaminase (ALT) (C009-1-1) and average total acid phosphatase (ACP) (A060-1-1) were estimated using the kits by following the manufacture instruction (Nanjing Jiancheng Bioengineering Institute, Nanjing, China)

\section{Antioxidant Parameters}

Antioxidant parameters such as glutathione (GSH), catalase (CAT), glutathione peroxidase (GPx), superoxide dismutase (SOD), glutathione- $S$-transferase (GST), malondialdehyde (MDA) and P. carbonyl were estimated by the standard method with minor modification. ${ }^{21-23}$

\section{Phase I Enzymes}

The previously mentioned method was used to quantify phase I enzymes such as cytochrome P450 reductase, NADH-cytochrome b5, cytochrome P420, and cytochrome b5 reductase. ${ }^{24-26}$

\section{Estimation of Cytokines}

The cytokines such as IL-1 $\beta$ (BMS6002TEN), IL-2 (BMS2212), IL-6 (BMS213-2) (Thermo Fisher Scientific Company, USA), IL-7, TNF- $\alpha$ (ab181421) and IL-10 (ab185986) (Abcam, UK) were scrutinized using the commercial ELISA kits following the manufacturer's instructions.

\section{Inflammatory Mediators}

The prostaglandin E2 (PGE2) (H099-1), COX-2 (H200) and NF-KB (H202) level in the serum and liver tissue of experimental rats were estimated using the ELISA kits following the manufacturer's instruction (Nanjing Jiancheng Bioengineering Institute, Nanjing, China).

\section{Histopathological Analyses}

The rat liver's left lobe was fixed in a $10 \%$ neutral buffered formalin solution (Thermo Fisher Scientific), then tissue processing, embedding, and sectioning were performed. For a histopathological study, five-micrometer portions of formalin-fixed and paraffin-embedded liver tissue were stained with hematoxylin and eosin (H\&E, Sigma-Aldrich).

\section{Gut Microbial}

At the end of the experiment, bacterial DNA was extracted from caecum samples using the QIAamp quick DNA Stool Mini Kit (Qiagen) according to the manufacturer's instructions. The V1-V2 region of 16S rDNA was amplified using Library quantification, and normalisation and pooling were performed using the 27Fmod (50-agrgtttgatymtggctcag-30) and 338R (50-tgctgcctcctaggagt-30) protocols, as defined. For more amplification, the Nextera XT Index Kit was used to connect Illumina sequencing adapters and multiplexing indices. Sequencing was carried out using a paired-end, 2300-bp cycle on an Illumina MiSeq sequencing system (Illumina) with MiSeq v3 reagent kits (600 Cycles, $15 \mathrm{~Gb}$ output), followed by fresh $\mathrm{NaOH}$ denaturation of a mixture of pooled libraries and Illuminagenerated PhiX control libraries. To perform quality control, FastQ files were created at the end of the run. Internally, PhiX Control was used to verify the accuracy of the run, and then each pair-end sequence was allocated to corresponding samples based on the multiplexing indexes. The command fastq-join from the 
package ea-utils was used to join pair end reads, which were then processed using the pipeline mentioned. Pandas put together raw paired end reads.

\section{Data Analysis}

The results are presented as mean standard error of the mean (SEM). One-way analysis of variance (ANOVA) and Dunnett's test were used to estimate the total variation in a collection of results. The significance level was set at $\mathrm{P}<0.05$.

\section{Result}

\section{Microscopical Observation}

Macroscopical observation was performed to identify the expansion or identification of HCC (Figure 1). Normal rats did not show any sign or symptom of hepatic nodules. DENinduced rats showed 138 hepatic nodules with 100\% tumor
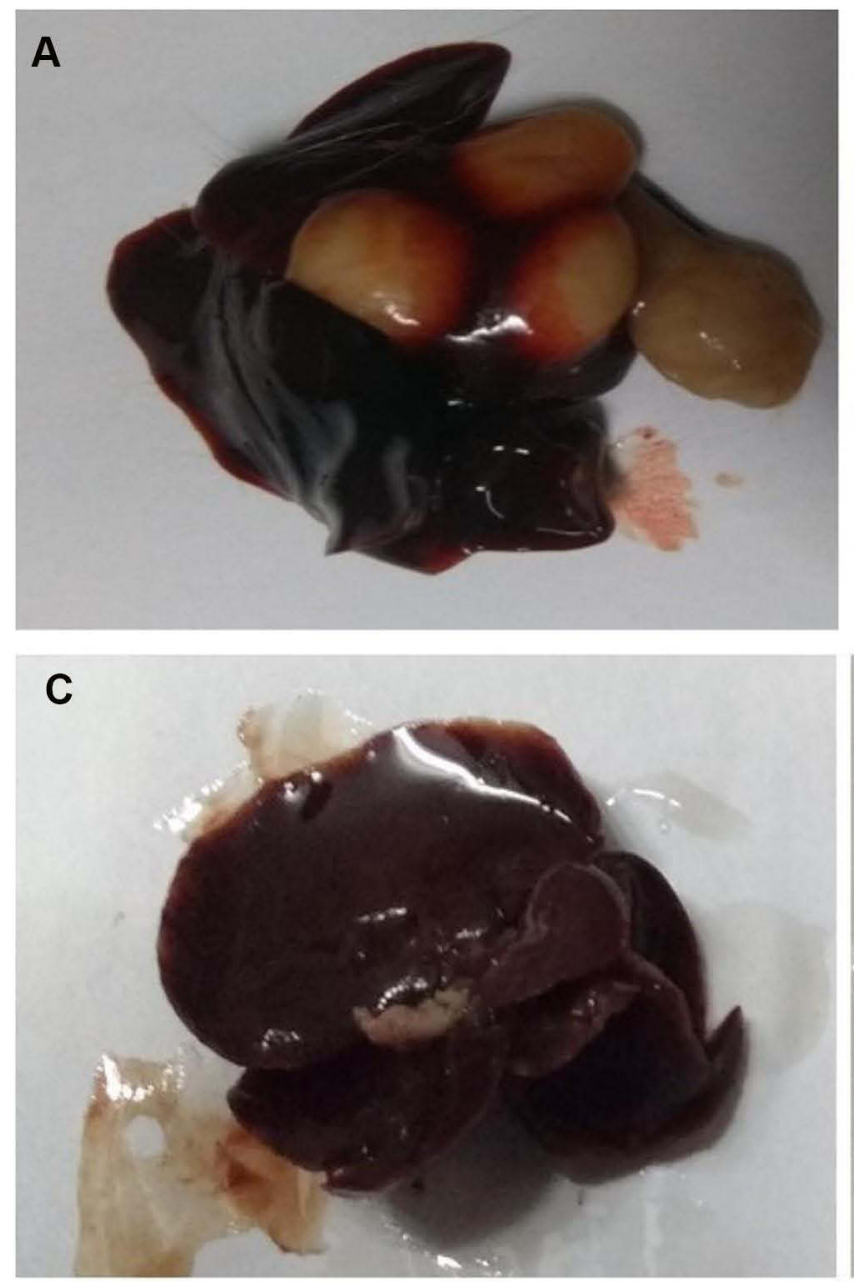

incidence. Curcumae (2.5 and $5 \mathrm{mg} / \mathrm{kg})$ treatment demonstrated hepatic nodules 83 , 45 with $58.38 \%$ and $45.45 \%$ hepatic nodules. Curcumae $(10 \mathrm{mg} / \mathrm{kg})$ illustrated the 12 hepatic nodules with $20 \%$ hepatic nodules incidence (Table 1 ).

Table 2 shows the hepatic nodules and different sizes of hepatic nodules of different experimental rats. No hepatic nodules were observed in the normal group of rats. DEN-induced HCC rats showed the $43.45 \pm 2.94$ average number of nodules with relative size $69(\leq 1 \mathrm{~mm}), 38$ $(<3 \mathrm{~mm}>1 \mathrm{~mm})$ and $31(\geq 3 \mathrm{~mm})$, respectively. Curcumae $(10 \mathrm{mg} / \mathrm{kg})$-treated rats showed a maximum reduction in the average number of nodules $6.83 \pm 1.45$ with relative size $7(\leq 1 \mathrm{~mm}), 4(<3 \mathrm{~mm}>1 \mathrm{~mm})$ and $1(\geq 3 \mathrm{~mm})$.

\section{Body Weight}

During the HCC, the body weight of the rats diminished due to expansion of disease. DEN-induced rats showed
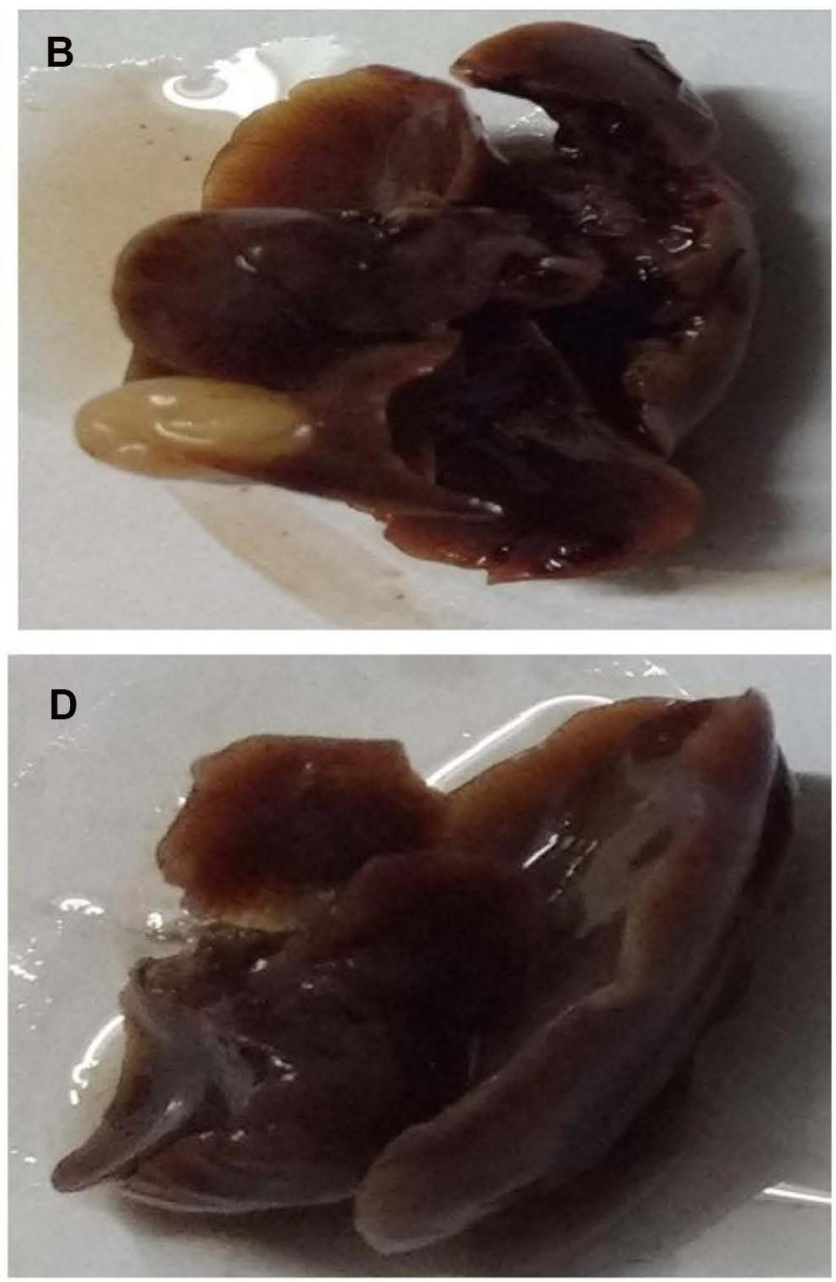

Figure I Hepatic nodules of different group of rats. (A) DEN control, (B) DEN + CU (2.5 mg/kg), (C) DEN + CU (5 mg/kg) and (D) DEN + CU (I0 mg/kg). Normal control rats did not show any sign of hepatic nodule. 
Table I Effect of Curcumae on the Development of Hepatic Nodules of DEN-Induced HCC Rats

\begin{tabular}{|l|c|c|c|c|}
\hline S. No. & Groups & $\begin{array}{c}\text { Number of Rats/Number of Rats with } \\
\text { Nodules }\end{array}$ & $\begin{array}{c}\text { Total Number of } \\
\text { Nodules }\end{array}$ & $\begin{array}{c}\text { Tumor Incidence } \\
\text { (\%) }\end{array}$ \\
\hline I & DEN & $10 / 10$ & 138 & 100 \\
2 & $D E N+C U(2.5 \mathrm{mg} / \mathrm{kg})$ & $12 / 7$ & 83 & 58.38 \\
3 & $\mathrm{DEN}+\mathrm{CU}(5 \mathrm{mg} / \mathrm{kg})$ & $11 / 5$ & 45 & 45.45 \\
4 & $\mathrm{DEN}+\mathrm{CU}(10 \mathrm{mg} / \mathrm{kg})$ & $10 / 2$ & 12 & 20 \\
\hline
\end{tabular}

Note: Normal control group rats did not showhepatic nodules.

Table 2 Effect of Curcumae Against DEN-Induced HCC Rats

\begin{tabular}{|c|c|c|c|c|c|c|}
\hline \multirow[t]{2}{*}{ S. No. } & \multirow[t]{2}{*}{ Groups } & \multirow{2}{*}{$\begin{array}{l}\text { Total Number of } \\
\text { Nodules }\end{array}$} & \multirow{2}{*}{$\begin{array}{c}\text { Average Number of Nodules/ Nodule- } \\
\text { Bearing Rats }\end{array}$} & \multicolumn{3}{|c|}{ Relative Size (\% of Number Size) } \\
\hline & & & & $\leq \mathrm{Imm}$ & $\begin{array}{l}<3 \mathrm{~mm} \\
>1 \mathrm{~mm}\end{array}$ & $\geq 3 \mathrm{~mm}$ \\
\hline I & DEN & 138 & $43.45 \pm 2.94$ & $69(50)$ & $38(27.53)$ & $31(22.46)$ \\
\hline 2 & $\mathrm{DEN}+\mathrm{CU}(2.5 \mathrm{mg} / \mathrm{kg})$ & 83 & $29.49 \pm 2.35$ & $45(54.21)$ & $28(33.73)$ & $10(12.04)$ \\
\hline 3 & $\mathrm{DEN}+\mathrm{CU}(5 \mathrm{mg} / \mathrm{kg})$ & 45 & $15.93 \pm 1.91$ & $24(53.33)$ & $13(28.89)$ & $8(17.77)$ \\
\hline 4 & $\mathrm{DEN}+\mathrm{CU}(10 \mathrm{mg} / \mathrm{kg})$ & 12 & $6.83 \pm 1.45$ & $7(58.33)$ & $4(33.33)$ & I (8.33) \\
\hline
\end{tabular}

Note: Normal control group rats did not showhepatic nodules.

reduction in the body weight of experimental rats. Curcumae-treated rats concentration-dependently showed augmented body weight (Figure 2A).

Figure 2B shows the boosted weight of liver tissue after the DEN treatment compared to normal rats. Curcumae treated rats showed a reduction in liver weight compared with DEN control group rats. Curcumae (10 mg/ $\mathrm{kg}$ ) treated rats showed a maximum reduction in liver weight compared to all treated group rats.

\section{Hepatic Parameter}

AFP is regarded as the gold standard for predicting HCC. DEN-induced rats showed increased levels of AFP, which was significantly $(\mathrm{P}<0.001)$ reduced via curcumae treatment. Curcumae $(10 \mathrm{mg} / \mathrm{kg})$ treatment exhibited the maximum reduction in the level of AFP. Other hepatic parameters such as ALP, AST, ACP and ALT considerably

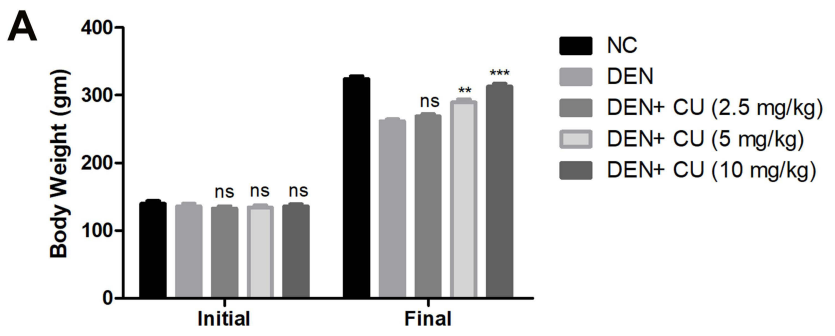

boosted during HCC. A similar result was observed in the DEN-induced HCC rats. Curcumae treatment substantially $(\mathrm{P}<0.001)$ decreased the amount of hepatic parameters, bringing them close to normal (Figure 3 ).

\section{Membrane-Bound Enzyme}

Figure 4 exhibits the effect of curcumae on the membranebound enzymes. The membrane-bound enzymes include $\mathrm{Ca}^{2+}$ ATPase, $\mathrm{Na}^{+} / \mathrm{K}^{+}$ATPase and $\mathrm{Mg}^{2+}$ ATPase decreased, after the DEN administration. Curcumae treatment significantly $(\mathrm{P}<0.001)$ dose-dependently increased the level of membranebound enzymes.

\section{Phase I Enzymes}

Figure 5 exhibits the effect of DEN and curcumae on phase I enzymes. Phase I enzymes such as NADPH cytochrome P450, cytochrome P420, NADPH cytochrome b5

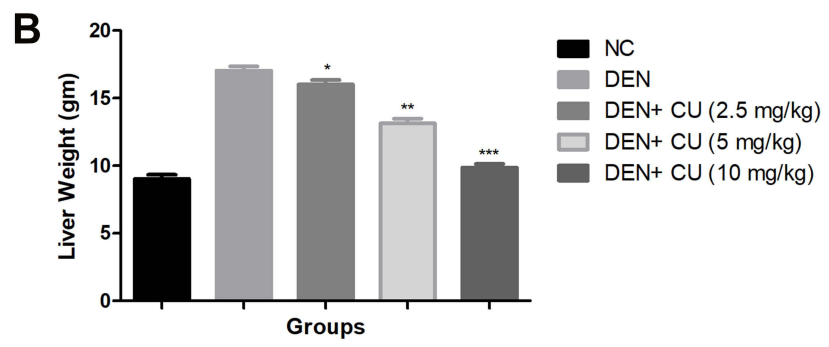

Figure 2 Effect of curcumae on the body weight and liver weight of obesity-induced hepatocellular carcinoma in rats. (A) Body weight and (B) liver weight. Tested group rats were compared with the DEN control group rats. $* \mathrm{P}<0.05, * * \mathrm{P}<0.01$ and $* * * \mathrm{P}<0.001$ were considered as significant, more significant and extreme significant, respectively. 

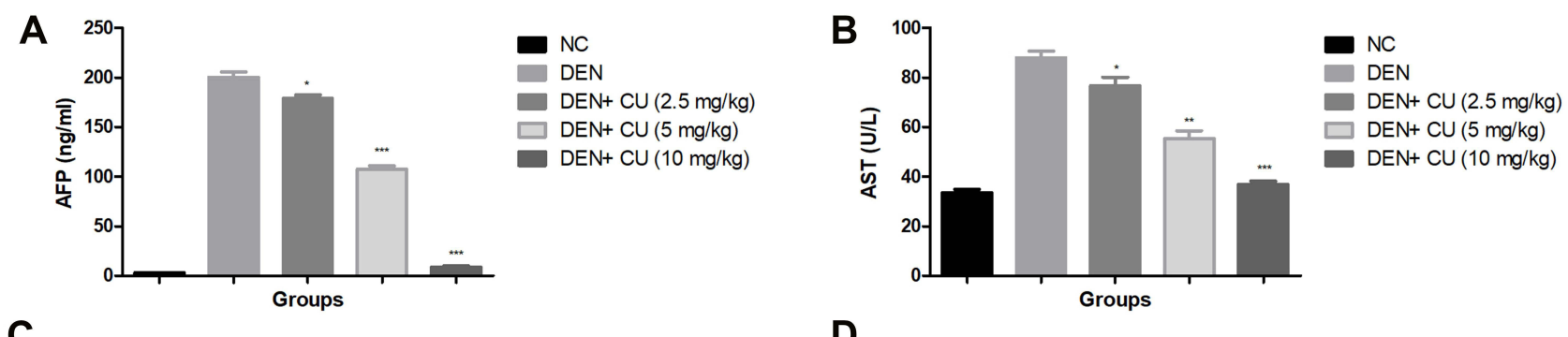

C

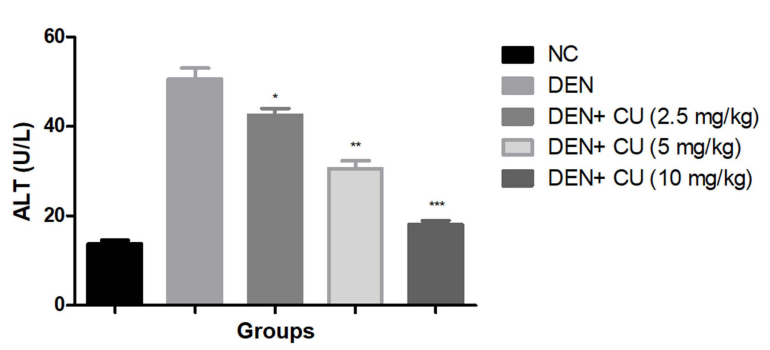

D

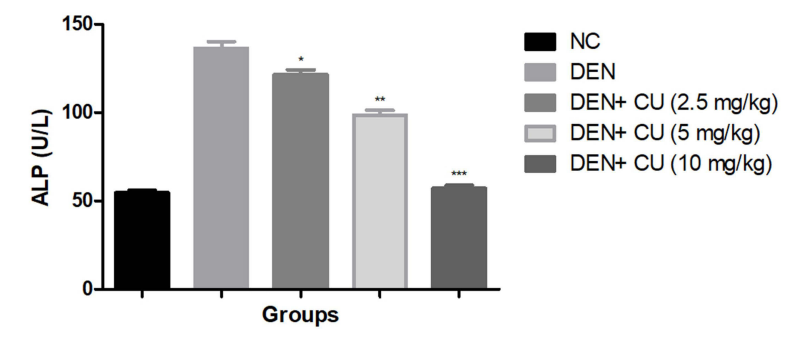

E

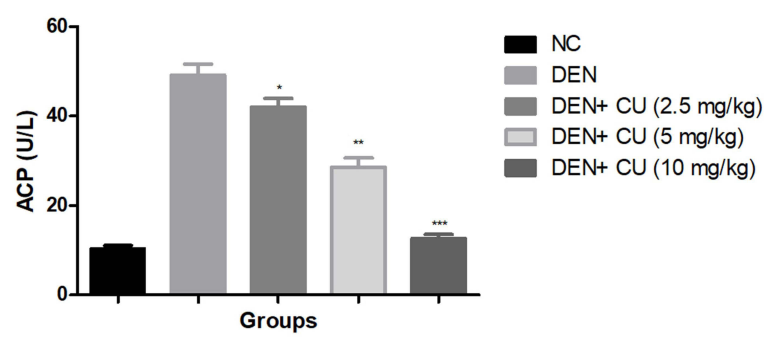

Figure 3 Effect of curcumae on the hepatic parameters of obesity-induced hepatocellular carcinoma in rats. (A) AFP, (B) AST, (C) ALT, (D) ALP and (E) ACP. Tested group rats were compared with the DEN control group rats. $* \mathrm{P}<0.05, * * \mathrm{P}<0.01$ and $* * * \mathrm{P}<0.00 \mathrm{I}$ were considered as significant, more significant and extreme significant, respectively.

and cytochrome b5 were estimated in the serum of experimental rats. DEN administration showed a reduction in the level of NADPH cytochrome P450, cytochrome P420 and enhancement in the level of cytochrome P420, NADPH cytochrome b5. Curcumae treatment modulates the level of phase I dose-dependent enzymes.

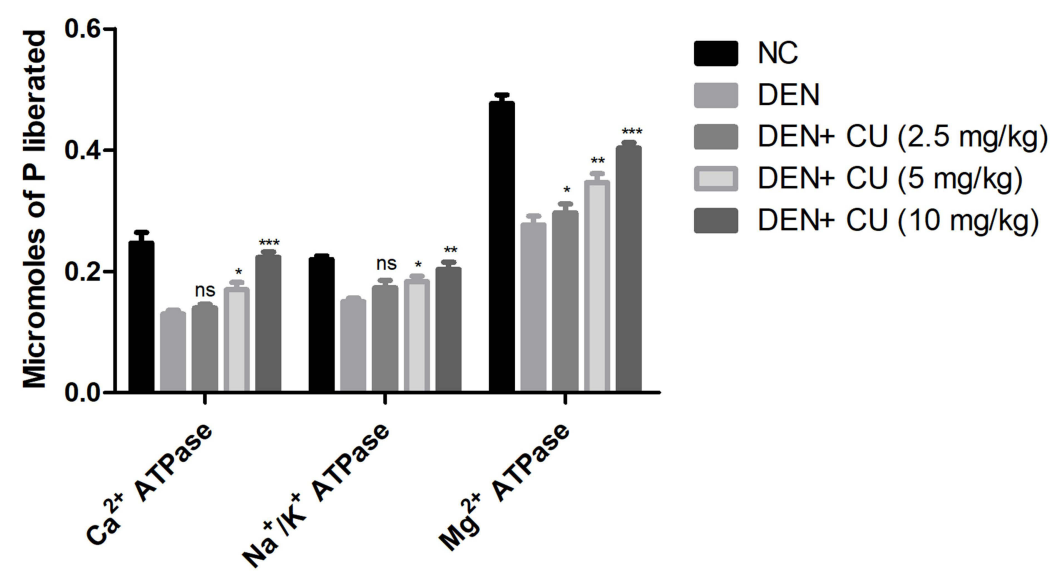

Figure 4 Effect of curcumae on the membrane-bound enzymes of obesity-induced hepatocellular carcinoma in rats. Tested group were compared with the DEN control group rats. $* \mathrm{P}<0.05, * * \mathrm{P}<0.01$ and $* * * \mathrm{P}<0.001$ were considered as significant, more significant and extreme significant, respectively. 

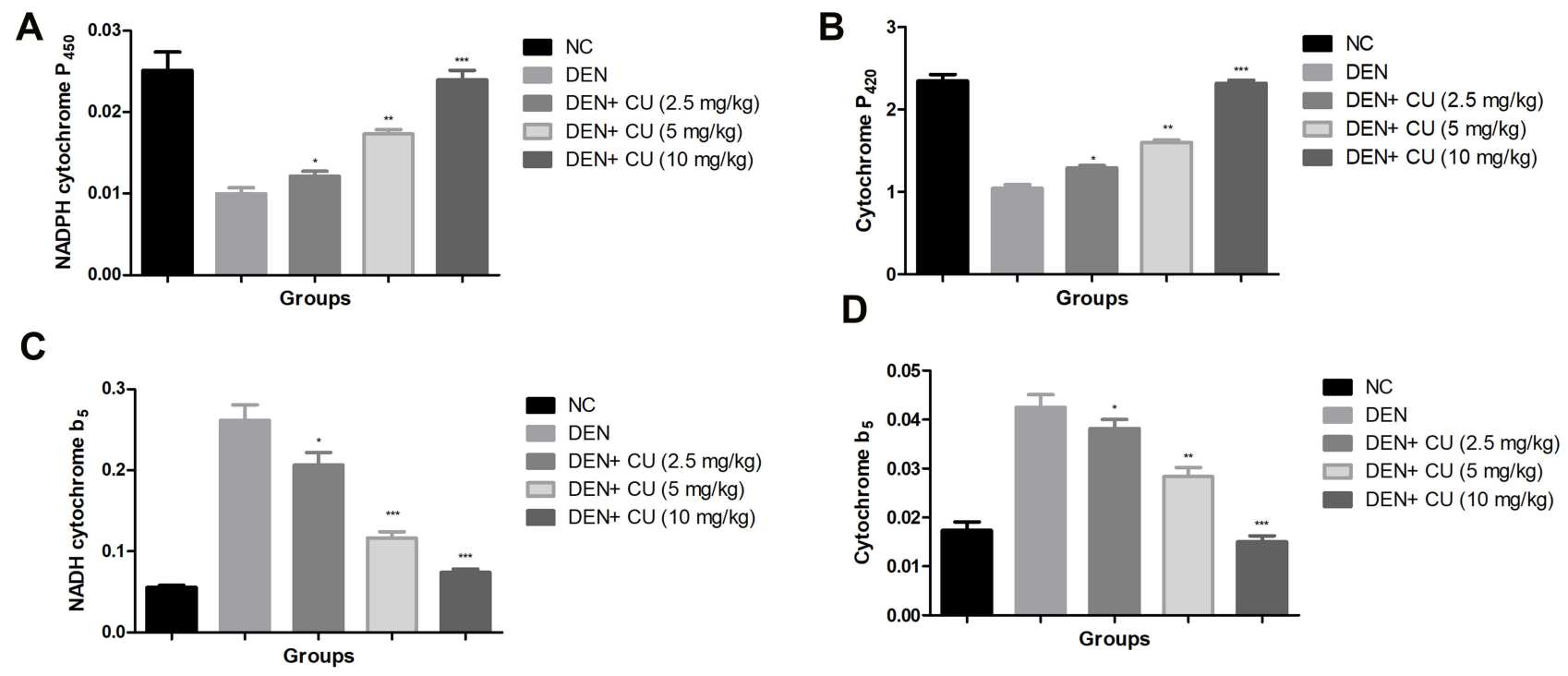

Figure 5 Effect of curcumae on the phase I and Phase II enzymes of obesity-induced hepatocellular carcinoma in rats. (A) NADPH cytochrome $P_{450}$, (B) cytochrome $P_{420}$, (C) NADPH cytochrome $b_{5}$ and (D) cytochrome $\mathrm{P}_{5}$. Tested group rate were compared with the $\mathrm{DEN}$ control group rats. $* \mathrm{P}<0.05$, $* * \mathrm{P}<0.0 \mathrm{I}$ and $* * * \mathrm{P}<0.00 \mathrm{I}$ were considered as significant, more significant and extreme significant, respectively.

\section{Antioxidant Parameters}

Antioxidant parameters, viz. MDA, GPx, P. carbonyl, GST, GSH, SOD, MPO and CAT, were estimated in all groups of rats. Figure 6 shows the boosted levels of MDA, P. carbonyl, GST, GSH, MPO and reduced levels of SOD, CAT in the DEN-induced HCC rats. Curcumae-treated rats showed suppressed levels of MDA, P. carbonyl, GST, GSH, MPO and up-regulated the level of SOD, CAT in DEN-induced HCC rats.

\section{Pro-Inflammatory Cytokines}

Pro-inflammatory cytokines, viz. IL-1 $\beta$, TNF- $\alpha$, IL-6, IL-2, IL-7 and IL-10, were estimated in the group rats. DENinduced rats showed increased levels of TNF- $\alpha$, IL-2, IL- $1 \beta$, IL-7, IL-6 and reduced level of IL-10 as comparison to normal rats. DEN-induced HCC rats treated with the curcumae significantly $(\mathrm{P}<0.001)$ increased the level of IL-10 and dose-dependently suppressed the level of TNF- $\alpha$, IL- $1 \beta$, IL2, IL-6, IL-7 (Figure 7).

\section{Inflammatory Mediators}

COX-2 and $\mathrm{PGE}_{2}$ were measured in the serum and liver tissue as inflammatory mediators. Figure 8 shows the increased levels of COX-2 and $\mathrm{PGE}_{2}$ in the serum and liver tissue in the DEN-induced HCC rats. Curcumaetreated rats showed reduced levels of $\mathrm{COX}-2$ and $\mathrm{PGE}_{2}$ in the serum and liver tissue in a dose- dependent manner.
Figure 9 exhibits the level of NF- $\mathrm{kB}$ in the serum and liver of the group rats. DEN-induced HCC rats showed an increased level of NF- $\mathrm{kB}$ in the serum and liver tissue. Curcumae treatment significantly $(\mathrm{P}<0.001)$ reduced the level of NF- $\kappa B$ in the serum and liver tissue in DENinduced $\mathrm{HCC}$ rats.

\section{Gut Microbiota}

To determine the gut microbiota composition alteration in the rat after the curcumae treatment, we used the 16S rDNA sequencing. For the identification of gut microbiota alteration, we determined the difference between the ACE, CHAO1 and OTUs in all experimental groups. Figure 10A shows a boosted richness of the intestinal microbiome. Figure 10B clearly indicates that curcumae treatment significantly increased microbial diversity. Figure $10 \mathrm{C}$ shows that the relative abundance of gram-positive bacteria increased while the relative abundance of gram-negative bacteria decreased. We estimate the gut microbiota in the fecal sample, we have observed the six major phyla of bacteria such as Tenericutes, Bacteroidetes, Deferribacteres, Firmicutes, Actinobacteria and Proteobacteria. In Figure 11, we compared the fecal sample microbiota. The reduction in the proportion of relative abundance of Bacteroidetes and Deferribacteres and higher proportion of Firmicutes were compared with the DEN group rats. It is well documented that 10 genera including Mucispirillum, Bacteroides, Lactobacillus Parabacteroides, Clostridium, Bifidobacterium and Escherichia were the most predominant. 
A

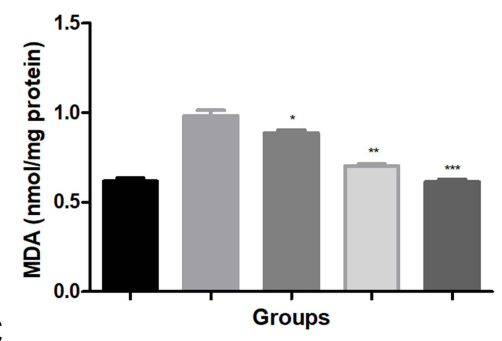

C

E

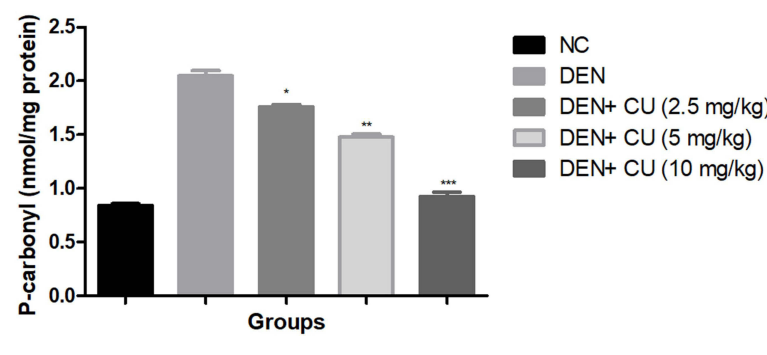

NC

DEN

DEN+ CU $(2.5 \mathrm{mg} / \mathrm{kg})$

$\square$ DEN+ CU $(5 \mathrm{mg} / \mathrm{kg})$

DEN+ CU (10 mg/kg)
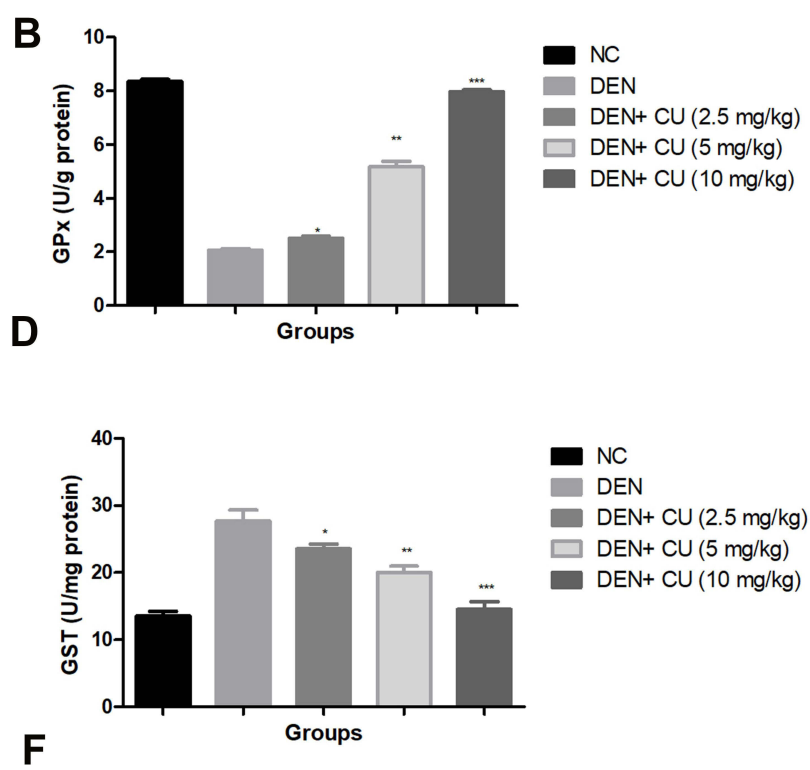

H
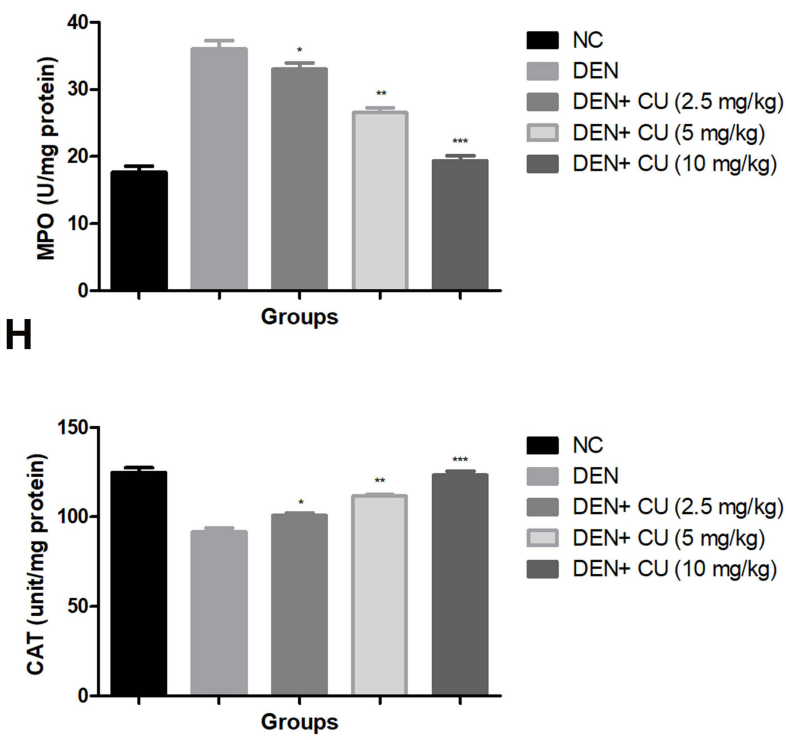

Figure 6 Effect of curcumae on the antioxidant parameters of obesity-induced hepatocellular carcinoma in rats. (A) MDA, (B) GPx, (C) p. carbonyl, (D) GST, (E) GSH, (F) MPO, (G) SOD and $(\mathbf{H})$ CAT. Tested group rats were compared with the DEN control group rats. where $* \mathrm{P}<0.05$, $* * \mathrm{P}<0.0 \mathrm{I}$ and $* * * \mathrm{P}<0.00 \mathrm{I}$ were considered as significant, more significant and extreme significant, respectively.

DEN-induced HCC rats showed reduced relative abundance of Bifidobacterium, Lactobacillus and increased relative abundance of Mucispirillum, Bacteroides, Parabacteroides and Clostridium, and curcumae treatment considerably increased the relative abundance of Bifidobacterium, Lactobacillus and reduced the relative abundance of Mucispirillum, Bacteroides, Parabacteroides and Clostridium.

Figure 11 shows that the curcumae treatment significantly suppressed the relative abundance of Clostridium genus. Figure 11 shows a reduction in the relative abundance of Clostridium, Deferribacteres phylum and its correspondent and Mucispirillum genus and Mucispirillum schaedleri species and enhanced the relative abundance of Clostridium species.

\section{Histopathology}

Figure 12 shows the expansion of cell necrosis, cell swelling, inflamed blood vessels, cytochrome with irregular shape, thick cords of hepatic parenchyma, pseudoacini and abrupt cells with rich sinusoids in the DEN-induced HCC rats. DEN-induced rats also showed hepatocytes are enclosed with the lipid droplets and also contained 
A

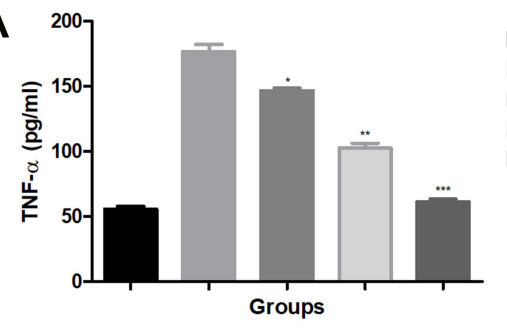

C

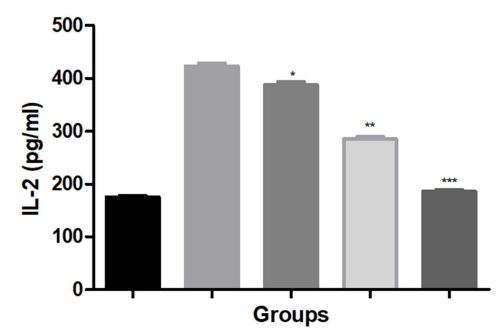

E

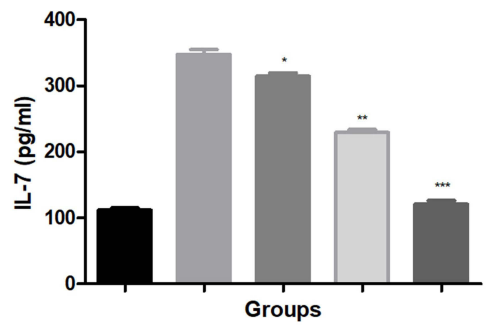

NC

DEN

DEN+ CU $(2.5 \mathrm{mg} / \mathrm{kg})$

$\square$ DEN+CU $(5 \mathrm{mg} / \mathrm{kg})$

DEN+ CU $(10 \mathrm{mg} / \mathrm{kg})$

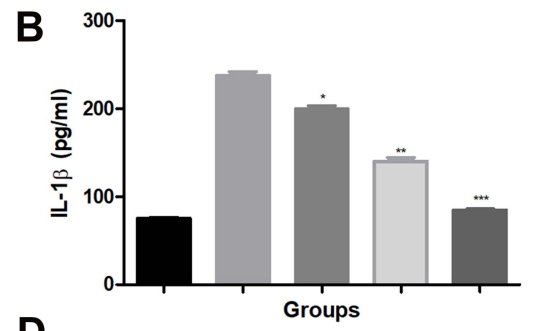

D

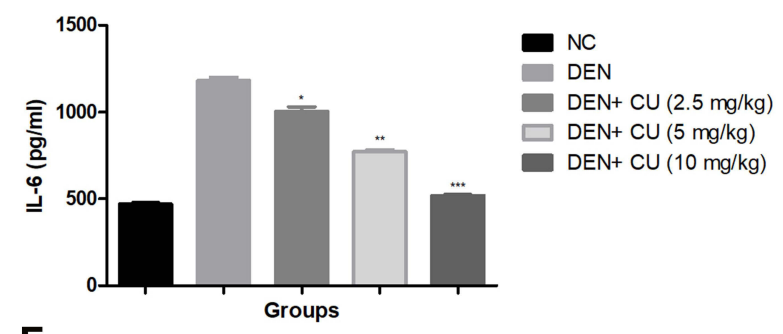

$\mathbf{F}$

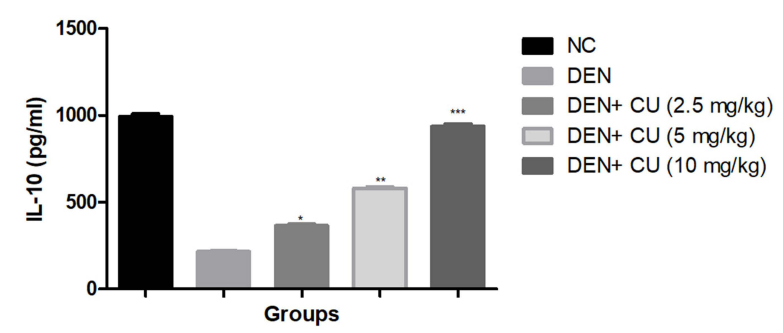

Figure 7 Effect of curcumae on the pro-inflammatory cytokines of obesity-induced hepatocellular carcinoma in rats. (A) TNF- $\alpha$, (B) IL-I $\beta$, (C) IL-2, (D) IL-6, (E) IL-7 and (F) IL-10. Tested group rats were compared with the DEN control group rats. ${ }^{*} \mathrm{P}<0.05, * * \mathrm{P}<0.01$ and $* * * \mathrm{P}<0.001$ were considered as significant, more significant and extreme significant, respectively.

A

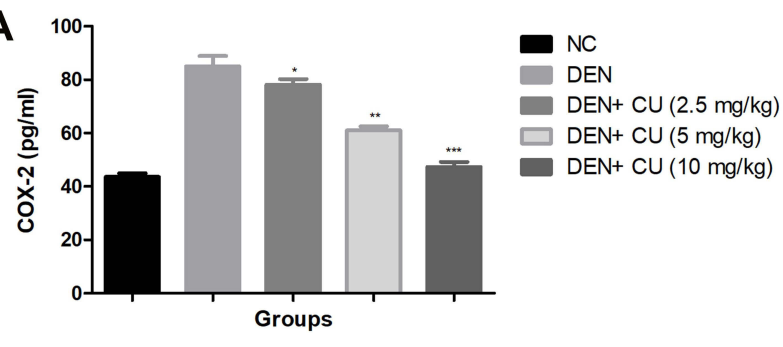

C

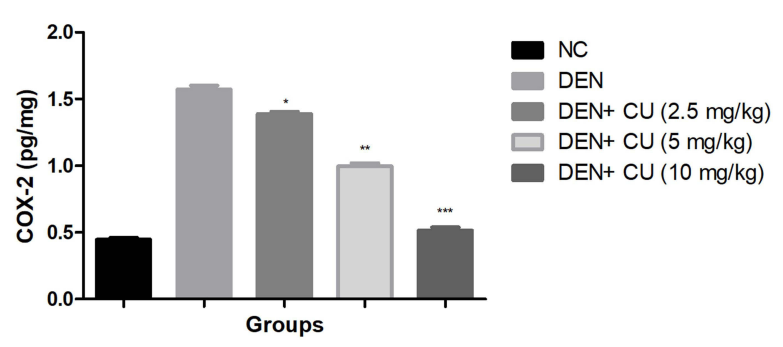

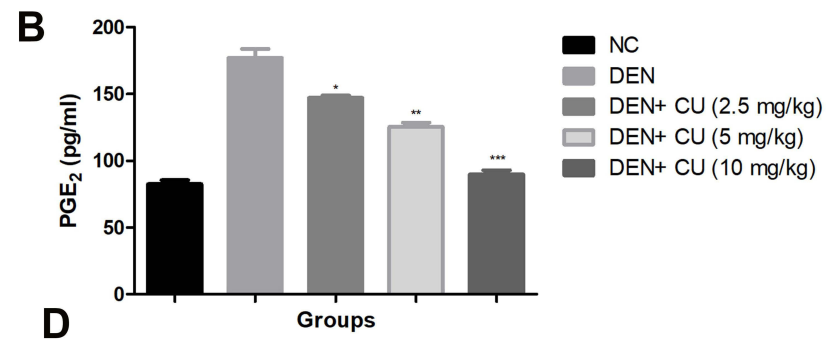

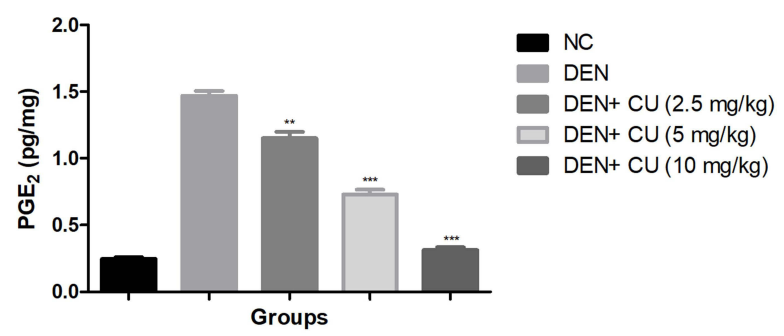

Figure 8 Effect of curcumae on the inflammatory parameters of obesity-induced hepatocellular carcinoma in rats. (A) COX-2 (serum), (B) PGE2 (serum), (C) COX-2 (liver tissue), (D) PGE2 (liver tissue). Tested group rats were compared with the DEN control group rats. $* \mathrm{P}<0.05$, $* * \mathrm{P}<0.01$ and $* * * \mathrm{P}<0.00 \mathrm{I}$ were considered as significant, more significant and extreme significant, respectively. 

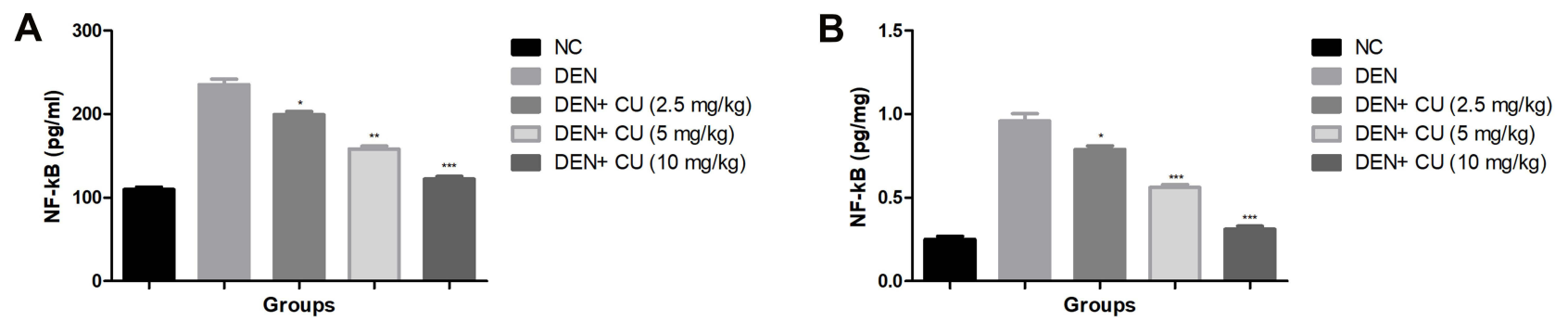

Figure 9 Effect of curcumae on the inflammatory parameters of obesity-induced hepatocellular carcinoma in rats. (A) NF- $\kappa B$ (serum) and (B) NF- $\kappa B$ (liver tissue). Tested group rats were compared with the $\mathrm{DEN}$ control group rats. $* \mathrm{P}<0.05$, $* * \mathrm{P}<0.01$ and $* * * \mathrm{P}<0.001$ were considered as significant, more significant and extreme significant, respectively.
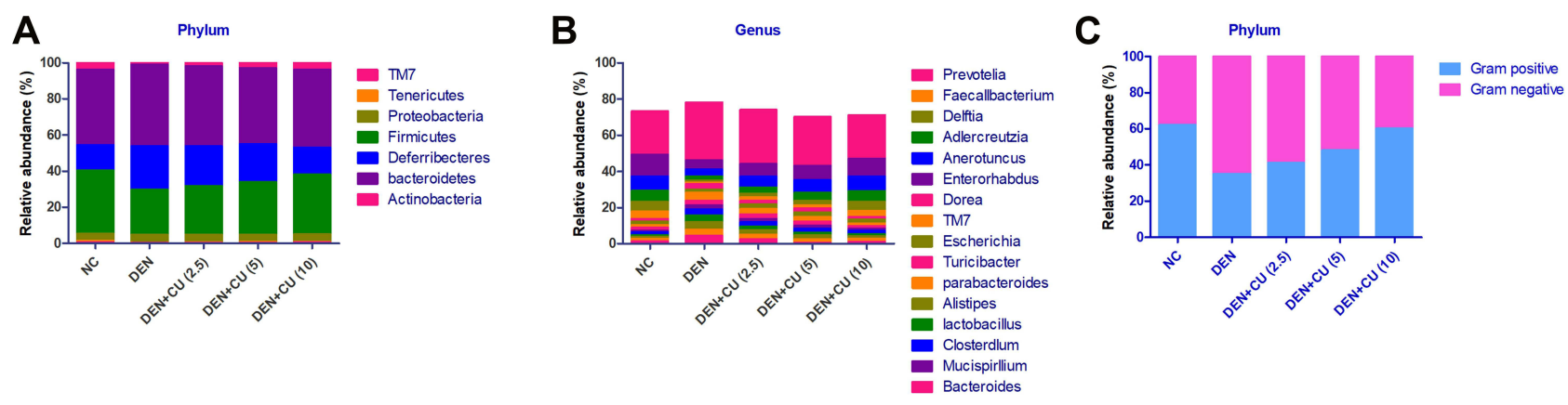

D

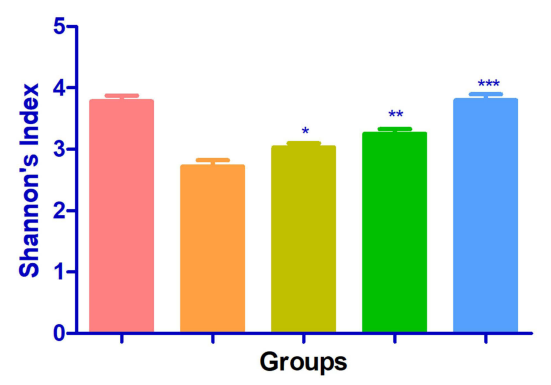

E

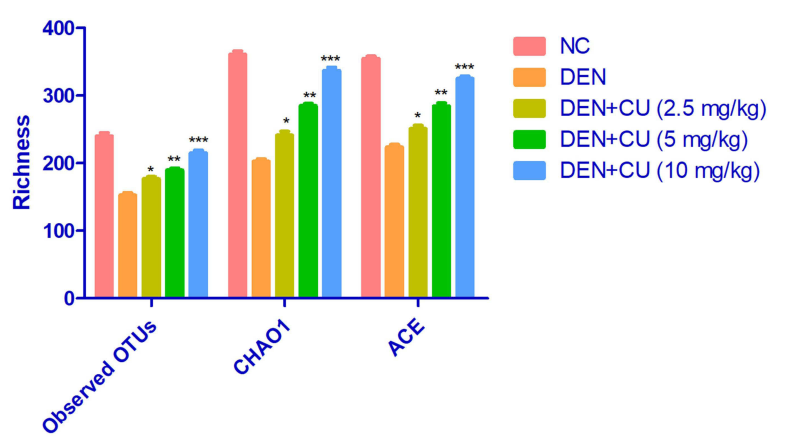

Figure 10 Effect of curcumae on the microbiota richness and distribution at genus, species and phylum level in obesity-induced hepatocellular carcinoma in rats. (A) relative abundance of major bacteria at phylum level, (B) relative abundance of major bacteria at genus level, (C) relative abundance of gram-negative or gram-positive bacteria, (D) Shannon index, (E) richness. Tested group rats were compared with the DEN control group rats. $* \mathrm{P}<0.05, * * \mathrm{P}<0.01$ and $* * * \mathrm{P}<0.00 \mathrm{I}$ were considered as significant, more significant and extreme significant, respectively.

eosinophilic masses in vacuolation guarded via cytoplasm. Hepatic stellate cells (HSCs) proliferated in the portal region of DEN rats, indicating focal proliferation. DENinduced rats treated with curcumae exhibited the preventive effect via reducing the number of necrotic cells and inflammatory cells, expanding proliferation in HSCs area, and enlarging karyomegaly. Curcumae treatment showed less focal proliferation and less microdroplets.

\section{Discussion}

HCC is a chronic progressive treatment resistance disease that affects the multiple molecular pathogenesis. ${ }^{27,28}$ During the induction of hepatocellular carcinoma, the major pathogenic mechanisms have been associated with the modulation in various cellular signaling pathways. ${ }^{29,30}$ This pathway helps with therapeutic effects via delay, reduction, or prevention of tumerogenesis effects. Through the increased knowledge of oncogenic processes, this signaling pathway regulates tumor cell differentiation, proliferation, metastasis and invasion, which has led to the identification of numerous possible therapeutic targets that help develop molecular targeted therapies. $^{8,31-33}$ Chronic inflammation of the liver tissue is a well-known risk factor for carcinogenesis, but the molecular relationship between hepatic fibrogenesis, inflammation and 


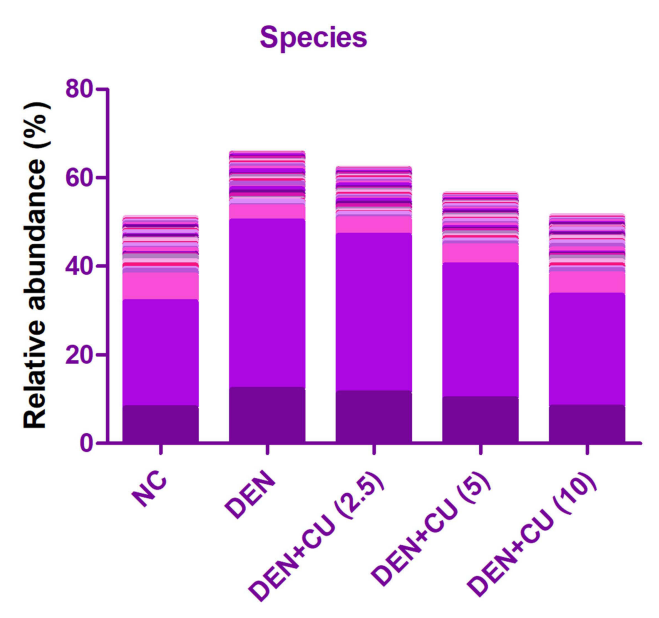

Mucispirllium S=schaedleri

Bacteroides acidifaciens

Lactobacillus reuteri

Lactobacillus johnsonii

Clostridium sp. ASF356

Lactobacillus sp. ASF360

Lactobacillus murinus

Clostridium sp. Clone-9

Clostridium sp. Clone-16

- Clostridium sp. Clone-17

Clostridium sp. Clone-27

Clostridium sp. ASF502

Clostridium fusiformis

Turicibacter sanguinis

Bacteroides dorei

Clostridium sp. Clone-47

Escherichia coli

Clostridium disporicum

Anaerotruncus colihomins

Clostridium cocleatum

Clostridium sp. cTPY 12

Clostridium sp. culture 57

Faecallbacterium prausnitzii

Clostridium sp. A9

Clostridium sp. ID4

Delftia lacustris

Bifidobacterium pseudolongum

Prevotella sp BI-42

paraabcteroides goldsteinii

Clostridum sp Clone-30

Eneroehabdus carcimuris

Dorea sp AP6

Bacteroides uniforms

Figure II Effect of curcumae on the relative abundance of major bacteria at species level in obesity-induced hepatocellular carcinoma in rats. Tested group rats were compared with the DEN control group rats.

hepatocellular carcinoma remains unclear. ${ }^{34,35}$ The liver tissue is a prime site for the inflammatory response to the intestinederived bacterial products to cross the intestinal barrier. Various investigations have shown that toll-like receptors (TLRs) and their pro-inflammatory mediators may be of the host inflammatory response to infection and play a significant role in human hepatic disease. ${ }^{23,36}$

Diethylnitramine (nitroso family compound), a wellknown hepato-carcinogenic agent, can be contained in water, tobacco smoke, agricultural chemicals, fried meals, cured meals, cheddar cheese, pharmaceutical and cosmetic products, and in trace amounts in baby bottle nipples. Studies suggest that the DEN-induced hepatocellular carcinoma in the rodents was similar to human hepatocellular carcinoma. ${ }^{23,24,29,37}$
Biochemical parameters are commonly used for estimating cancer conditions. Biochemical parameters are also used for the examination, diagnosis, and progression of disease, and finally explain the effect or response of a drug or therapy. ${ }^{27,38}$ During the disease/cancer, the activity of these enzymes is altered. The altered levels of these biochemical enzymes are correlated with the various transformed cells during cancer. During liver cancer, an alteration in the transport function that is regulated via cell organelles of hepatocytes occurred. Hepatic enzymes start secretion into the serum due to alteration of plasma membrane permeability and this increases the level of these enzymes in the blood and cells. ${ }^{11,28,39}$ AFP (marker of hepatic cancer) is a gold marker, which is commonly used for estimating HCC. During the HCC, the level of AFP was considerably boosted. The shape or size of the 

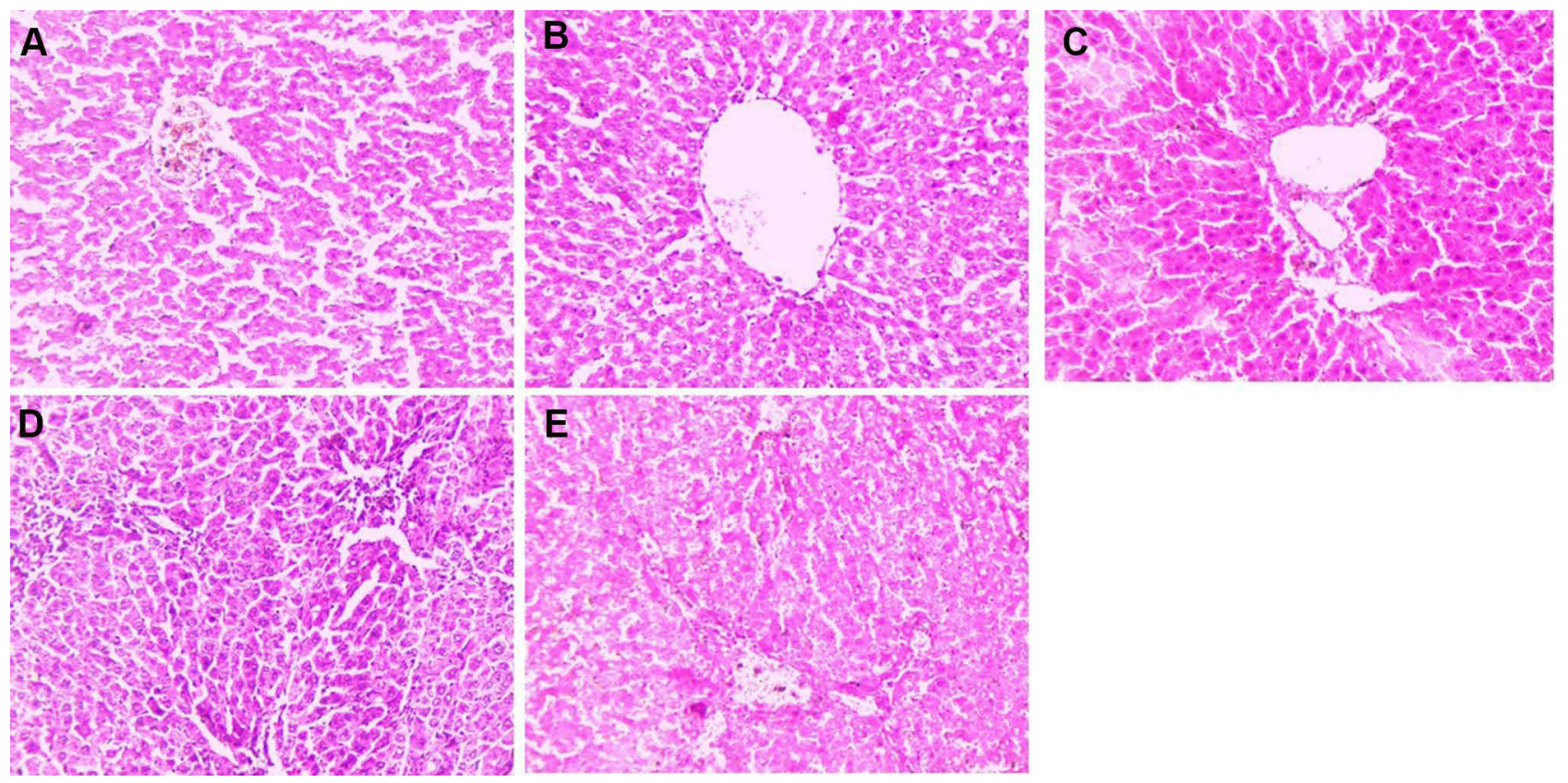

Figure 12 Effect of curcumae on the histopathology of obesity-induced hepatocellular carcinoma in rats. (A) Normal control, (B) DEN, (C) DEN + CU (2.5 mg/kg), (D) DEN + CU $(5 \mathrm{mg} / \mathrm{kg})$ and $(E) D E N+C U(10 \mathrm{mg} / \mathrm{kg})$. Tested group rats were compared with the DEN control group rats.

AFP is similar to the other serum proteins, but the level of AFP is found in minute quantities in a normal patient. The level of AFP increased 50-100 times during HCC. ${ }^{29,40}$ In patients with cirrhosis caused by hepatitis, AFP is also used to diagnose chronic and acute viral hepatitis. ${ }^{29,40}$ In patients with cirrhosis caused by hepatitis, AFP is also used to diagnose chronic and acute viral hepatitis. $^{8,29,33,40}$ DEN-induced HCC rats showed increased levels of AFP and curcumae treatment significantly $(\mathrm{P}<0.001)$ reduced the level of AFP and reached almost near to the normal level. Hepatic enzymes such as ALT, AFP, AST, GGT and ALP boosted after the DEN administration and caused hepatic dysfunction. AST and ALT (hepatic enzymes) are related to the conversion of amino to keto acids and contribute to the expansion of HCC. In the current experimental study, we observed that DEN treatment stimulates the liver markers that lead to liver tissue damage. DEN-induced group rats showed increased levels of AFP, ALT, AST, ALP and GGT.

In the current investigation, DEN-induced HCC and augmented the oxidative stress in the liver and altered the endogenous antioxidant enzymes. DEN reduced the endogenous antioxidant defense system by considerably boosting the level of MDA (oxidative stress marker) and reducing the levels of SOD, GPx, GSH and GR (free radical scavenging antioxidant). ${ }^{34,41}$ Previous studies suggest that DEN was metabolized in hepatic tissue via the action of cytochrome p450 enzymes and finally increased oxidative stress. ${ }^{23,36,42}$ During the metabolism in hepatic tissue and reactive with the various metabolites, these are mainly responsible for the hepatic toxic effects. DEN bioactivates the ethyldiazonium ion, which alkylates DNA bases to form promutagenic adducts like O6-ethyldeoxyguanosine and $\mathrm{O} 4$ and O6ethyldeoxythymidine. ${ }^{23,24,43}$ These ROS induce oxidative stress and cytotoxicity by killing biomolecules like DNA, lipids, and proteins. The reduced levels of GSH and GSHdependent enzymes, GR and GPx, commonly observed due to suppression in their biosynthesis during $\mathrm{HCC}$ injury. ${ }^{37,44,45}$ The levels of these enzymes are reduced due to excessive usage of free radical scavenging during the scavenging of free radicals that are generated during the metabolism of DEN in the liver. Furthermore, since GSH is a critical co-factor for these enzymes, the reduction of cellular GSH may have suppressed the activities of GSHdependent enzymes such as GR and GPx.

Previous studies have shown that a high level of lipid peroxidation (LPO) leads to the reduction of body weight due to liver failure. ${ }^{43,46}$ The main effect of carcinogenesis is the induction of oxidative stress. The endogenous antioxidant contributes to the stable free radical level via donating an electron or scavenging the free radical. ${ }^{47,48}$ Endogenous antioxidants have been identified and distinct as substances that have a concentration lower than the substrate, which is susceptible to reducing ROS generation 
and also capable of delaying oxidation. Antioxidants play a significant role in scavenging the tissue and cells, thereby protecting cellular and tissue damage from disease. ${ }^{36,49}$ Umbelliferone, a coumarin derivative mainly found in Agele marmilosa, is well known antioxidant enzymes. Kumar et al showed that the DEN administration boosted the lipid peroxidation reaction along with the suppression of endogenous antioxidant enzymes. ${ }^{33}$ Lipid peroxidation is a well-known process that starts via free radical attack on one or more fatty acids and boosts/generates the numerous ranges of toxic metabolites including 4-hydroxynonenal and malondialdehyde. ${ }^{11,30}$ These metabolites directly or indirectly attack the DNA and cause carcinogenicity and mutation. DEN-induced $\mathrm{HCC}$ is directly responsible for the boosted oxygen free radical metabolism. $^{40,50}$

In the current experimental study, we found that the boosted level of LPO after the treatment of DEN and curcumae reduced the LPO level either by scavenging the free radical or by suppressing the formation of LPO metabolites. ${ }^{27,39}$ A change in ROS metabolism in hepatic tissue was estimated via scrutinizing the endogenous antioxidant enzymes, including CAT and SOD. After the DEN administration, the activities of CAT and SOD were due to the generation of free radicals, and the biological system needed antioxidants to scavenge free radicals. SOD catalyzes the dismutation of $\mathrm{O}_{2}$ to $\mathrm{H}_{2} \mathrm{O}_{2}$, which later on is deactivated into water via CAT. ${ }^{11,30} \mathrm{CAT}$ and SOD are the first-line endogenous antioxidant enzymes that eliminate or scavenge free radicals. Reduction of the activities of these enzymes may lead to enhanced hydrogen peroxide $\left(\mathrm{H}_{2} \mathrm{O}_{2}\right)$ and superoxide anion $\left(\mathrm{O}_{2}\right)$. Due to an increase in the level of free radicals, which starts the generation of hydroxyl radicals $(\mathrm{OH})$, and finally induces lipid peroxidation. $^{8,32,40}$ This investigation shows a reduction in antioxidant enzyme levels in DEN-induced rats, which might have led to the initiation of HCC.

According to a previous study, the DEN causes an increase in LPO and GSH, which may minimize DNA carcinogen interaction by providing a large nucleophilic pool for electrophilic carcinogens (DEN). ${ }^{33,41} \mathrm{GSH}$ provides the SH group, which neutralizes the electrophilic site and makes the metabolite more water soluble. The increased activities of endogenous antioxidant enzymes have been identified, as NADPH, which is required for GSH production, is produced via the pentose phosphate pathway. ${ }^{34,42,49}$ Curcumae has the potential to increase glucose absorption in cells, which could lead to further glucose being taken in by cells and eventually serving as fuel for both the oxidative phosphorylation and pentose phosphate pathways, raising cellular levels. NADPH/ $\mathrm{NADP}^{+}\left(\mathrm{NADPH} / \mathrm{NADP}{ }^{+}\right)$. DEN boosted the activity of GR, which also increased the GSH level. ${ }^{1}$ In this study, we found that the increased level of antioxidant enzymes such as GPx, SOD, CAT, GR and reduced the level of nonenzymatic antioxidant enzymes includes GSH after the curcumae treatment. Curcumae treatment significantly $(\mathrm{P}<0.001)$ reduced lipid peroxidation by either scavenging the free radical or maintaining the ROS integrity and cell membrane permeability, thus, protecting the tissues and cells against the oxidative damage induced by free radicals. Curcumae's potential effect is explained not only by its antioxidant properties but also by its ability to inhibit the cytochrome P450 isoenzyme 2E1 (CYP2E1), which metabolises DEN and causes lipid peroxidation and ROS generation. $^{44,51,52}$

DEN administration causes the secretion of proinflammatory cytokines from the liver tissue. Interleukin family cytokines, such as IL- $1 \beta$ considered as the potent pro-inflammatory cytokines, play a potent role in the expansion and progression of inflammatory reactions. ${ }^{28,39}$ According to numerous studies, a high level of IL-1 $\beta$ activates a local inflammatory response by increasing tumor invasiveness and tissue damage linked to inflammation. Clinical investigation confirmed that the IL-1 $\beta$ considerably boosted during HCC expansion. $^{31,40,50}$ Pro-inflammatory cytokines such as IL-6 and IFN- $\gamma$ are released via hepatocytes in response to DEN treatment that showed liver toxicity, while curcumae treatment showed a reduction in the level of proinflammatory cytokines and improved the liver toxicity. Similarly, cytokines such as IL-6 are considered as the tumor marker for HCC. ${ }^{32,33}$ It also helps identify a subset of HCC patients with high AFP levels that may serve as a tumor marker. DEN administration showed an increased level of IL-6, suggesting the HCC expansion. Other cytokines such as IFN- $\gamma$ are considered as the antiproliferative and immunomodulatory agent. In the hepatic tissue, IFN- $\gamma$ fate of hepatocytes toward either cell cycle arrest or apoptosis. ${ }^{34,35,41}$ The increased level of IFN- $\gamma$ activated lymphocytes includes natural killer $\mathrm{T}$ cells, NK cells and $\mathrm{T}$ lymphocytes, suggesting the inflammatory reaction and hepatic tissue damage. DENinduced rats showed increased levels of proinflammatory cytokines and curcumae significantly $(\mathrm{P}<0.001)$ reduced the cytokines. NF- $\kappa \mathrm{B}$ plays an 
important role in the tumor-related inflammation. The various ranges of genes are regulated via $\mathrm{NF}-\kappa \mathrm{B}$ such as encoding cytokines such as IL-1 (IL-2, IL-6, and IL12), inducible effector enzymes (PGE2, COX-2 and iNOS) and chemokines (IL-8 and MCP1). ${ }^{25,42,49}$ In the current experimental study, curcumae-reduced DEN induced hepatic inflammation via reduction of the cytokines and inflammatory mediators.

Hepatic tissue is most linked to the intestinal tract by protecting the detrimental bacterial metabolites and their composition from portal circulation. ${ }^{1}$ A previous study suggests that the reduced gut microbial bacteria was observed in the NASH patients as compared with normal people, which is a significant factor for the induction of HCC, a long-term upshot of inflammation, fibrosis and liver injury. In the current experimental study, we found that the HCC control group rats showed a reduction in the level of gut microbiota and that curcumae treatment considerably increased the diversity and richness of gut microbiota. The gut microbiota contains two types of bacteria (gram-positive and gram-negative). Previous reports suggest that Gram-negative bacteria can enhance the production of hepatotoxic products, including lipopolysaccharide. In this study, DEN group rats showed an increased tendency to gram-negative bacteria and boosted lipopolysaccharide production. Curcumae-treated reduced gram-negative bacteria tendency and suppressed lipopolysaccharide production, which causes inflammation via boosting cell proliferation, developing resistance to cell apoptosis and activating the Toll-like receptor 4. Mucispirillum is linked to inflammatory reactions and enhanced serum leptin levels. We have observed the three main phylums and only the Deferribacteres (phylum) and represents species and genes as well as the relative abundance of Mucispirillum and Mucispirillum schaedleri, which were considerably reduced after the curcumae treatment. Curcumae also reduced the Mucispirillum species, which showed a reduction in the inflamed reactions/cytokines and suggests the antiinflammatory effects. Curcumae treatment also reduced the changes of Clostridium genus. Clostridium, Clostridium species and increased the Clostridium sp. Clone. Previous studies have well documented that boosted Clostridium species are involved in the suppression of fatty acid oxidation and boosting hepatic lipogenesis, which showed that Clostridium sp. may be a potential target of curcumae to treat hepatic cancer. ${ }^{1}$ Although, the curcumae treatment enhanced the diversity and richness of gut microbiota and improved the condition of various potential bacteria, which in turn helped in the regulation of hepatic lipid metabolism, hepatic circadian clock and inflammation via gut liver interaction.

\section{Conclusion}

Curcumae considerably showed a chemoprotective effect against DEN-induced HCC rats. Curcumae significantly $(\mathrm{P}<0.001)$ down-regulated the AFP level and other hepatic enzymes, including ALT, ALP, ACP and AST. Curcumae significantly $(\mathrm{P}<0.001)$ increased the activity of membrane-bound enzymes. Curcumae altered the endogenous antioxidant level, phase I enzyme, and proinflammatory cytokine levels in the DEN-induced HCC rats. Curcumae reduced the level of inflammation mediators such as COX-2, NF- $\kappa \mathrm{B}$ and $\mathrm{PGE}_{2}$ in the serum and liver tissue. Curcumae treatment considerably altered the gut microbiota and suppressed the growth of the HCC. The chemoprotective effect of curcumae could be attributed to

- Reduced the AFP level (gold marker of hepatic cancer) along with reduction of hepatic enzymes.

- Increased the body weight and reduced the liver weight.

- Improved endogenous antioxidant level and phase I enzymes.

- Reduced the level of pro-inflammatory cytokines.

- Down-regulated the inflammatory mediators in the serum and tissue.

- Altered the gut microbiota.

\section{Data Sharing Statement}

The data that support the findings of this study are available from the corresponding author upon reasonable request.

\section{Ethics Approval and Consent to Participate}

All the experimental protocols were approved from the First People's Hospital of Lianyungang City. All the protocols are carried out in accordance with the Institute guidelines.

\section{Author Contributions}

All authors made a significant contribution to the work reported, whether that is in the conception, study design, execution, acquisition of data, analysis and interpretation, 
or in all these areas; took part in drafting, revising or critically reviewing the article; gave final approval of the version to be published; have agreed on the journal to which the article has been submitted; and agree to be accountable for all aspects of the work.

\section{Funding}

The current experimental study was self-funded.

\section{Disclosure}

All the authors declare no conflicts of interest in this work.

\section{References}

1. Xia H, Liu C, Li C, et al. Dietary tomato powder inhibits high-fat diet - promoted hepatocellular carcinoma with alteration of gut microbiota in mice lacking carotenoid cleavage enzymes. Cancer Prev Res. 2018;11:797-810. doi:10.1158/1940-6207.CAPR-18-0188

2. Ming X, Tan RX. Natural product reports interaction between gut microbiota and ethnomedicine constituents. Royal Soc Chem 2019;36:788-809.

3. Kumar V, Rahman M, Gahtori P, Al-abbasi F, Anwar F, Kim HS. Expert opinion on drug delivery current status and future directions of hepatocellular carcinoma-targeted nanoparticles and nanomedicine. Expert Opin Drug Deliv. 2021;18:1-22.

4. Naqvi S, Omar T, Kumar V, et al. Biomedicine \& pharmacotherapy: a cross-talk between gut microbiome, salt and hypertension. Biomed Pharmacother. 2021;134:111156. doi:10.1016/j.biopha.2020.111156

5. Rahman M, Almalki H, Afzal O, et al. Cationic solid lipid nanoparticles of resveratrol for hepatocellular carcinoma treatment: systematic optimization, in vitro characterization and preclinical investigation. Int J Nanomed. 2020;15:9283.

6. Alharbi S, Alruwaili NK, Alotaibi H, Alzarea AI, Almalki WH. Implications of solid lipid nanoparticles of ganoderic acid for the treatment and management of hepatocellular carcinoma. J Pharm Innov. 1872;16(2):359-370.

7. Rahman M, Almalki WH, Kazmi I, et al. Development and validation of a new UPLC-MS/MS method for quantification of ganoderic acid-A loaded nanolipidic carrier in rat plasma and application to pharmacokinetic studies. $J$ Chromatogr B. 2021;1163:122501. doi:10.1016/j.jchromb.2020.122501

8. Jin X, Zhao T, Shi D, Bao M, Qiying Y. Protective role of fucoxanthin in diethylnitrosamine-induced hepatocarcinogenesis in experimental adult rats. Drug Dev Res. 2019;80:209-217.

9. Kumar V, Ahmed D, Verma A, Anwar F, Ali M, Mujeeb M. Umbelliferone $\beta$-D-galactopyranoside from Aegle marmelos (L.) corr. an ethnomedicinal plant with antidiabetic, antihyperlipidemic and antioxidative activity. BMC Complement Altern Med. 2013;13:273. doi:10.1186/1472-6882-13-273

10. You Y, Zhu F, Li Z, Zhang L, Xie Y, Chinnathambi A, Alahmadi TA, $\mathrm{Lu}$ BPhyllanthin prevents diethylnitrosamine (DEN) induced liver carcinogenesis in rats and induces apoptotic cell death in HepG2 cells. Biomed Pharmacother. 2021.137:111335.

11. Shirakami Y, Gottesman ME, Wsb Ã. Diethylnitrosamine-induced hepatocarcinogenesis is suppressed in lecithin: retinol acyltransferase-deficient mice primarily through retinoid actions immediately after carcinogen administration. Carcinogenesis. 2011;33:1-7

12. Granado-serrano AB, Martín MÁ, Bravo L, Ramos S. Quercetin attenuates TNF-induced inflammation in hepatic cells by inhibiting the NF-кB pathway. Nutr Cancer. 2012;64:1-37.
13. Kakehashi A, Wei M, Fukushima S, Wanibuchi H. Oxidative stress in the carcinogenicity of chemical carcinogens. Cancers. 2013;5:1332-1354.

14. Dai Z, Tang W, Lu W, et al. Antiproliferative and apoptotic effects of $\beta$-elemene on human hepatoma HepG2 cells. Cancer Cell Int. 2013;13:1. doi:10.1186/1475-2867-13-27

15. Singh R, Afzal M, Kazmi I, Anwar F. Talc used in anticancer drugs is promoter for diabetes in hepatocellular carcinoma induced rats. Eur $J$ Cancer. 2014;50:247-248. doi:10.1016/j.ejca.2013.09.020

16. Hou J, Fang F, Kang S, Wang Z, Yang Y. Curcumin from Jianghuang (Rhizoma Curcumae Longae) protects against exposure to ultraviolet $\mathrm{B}$ by antioxidation and attenuating mitochondrion-dependent apoptosis. J Tradit Chin Med. 2020;40:782-791.

17. Liu H, Peng YY, Liang FY, et al. Protective effects of traditional Chinese medicine formula NaoShuanTong capsule on haemorheology and cerebral energy metabolism disorders in rats with blood stasis. Biotechnol Biotechnol Equip. 2014;28:140-146. doi:10.1080/13102818.2014.901678

18. Shi J, Tian J, Zhang X, et al. A combination extract of ginseng, epimedium, polygala, and tuber curcumae increases synaptophysin expression in APPV717I transgenic mice. Chin Med. 2012;7. doi:10.1186/1749-8546-7-13

19. Liu Z, Huang P, Law S, Tian H, Leung W, Xu C. Preventive effect of Curcumin against chemotherapy-induced side-effects. Front Pharmacol. 2018;9. doi:10.3389/fphar.2018.01374

20. Akbari S, Kariznavi E, Jannati M, Elyasi S, Tayarani-Najaran Z. Curcumin as a preventive or therapeutic measure for chemotherapy and radiotherapy induced adverse reaction: a comprehensive review. Food Chem Toxicol. 2020;145:111699. doi:10.1016/j.fct.2020.111699

21. Bhatia N, Gupta P, Singh B, Koul A. Lycopene enriched tomato extract inhibits hypoxia, angiogenesis, and metastatic markers in early stage $\mathrm{N}$-nitrosodiethylamine induced hepatocellular carcinoma. Nutr Cancer. 2015;67:1270-1277. doi:10.1080/01635581.2015.1087040

22. Verma A, Singh D, Anwar F, Bhatt PC, Al-Abbasi F, Kumar V. Triterpenoids principle of Wedelia calendulacea attenuated diethynitrosamine-induced hepatocellular carcinoma via down-regulating oxidative stress, inflammation and pathology via NF-kB pathway. Inflammopharmacology. 2018;26:133-146. doi:10. 1007/s10787-017-0350-3

23. Singh D, Singh M, Yadav E, et al. Amelioration of diethylnitrosamine (DEN)-induced hepatocellular carcinogenesis in animal models: via knockdown oxidative stress and proinflammatory markers by Madhuca longifolia embedded silver nanoparticles. RSC Adv. 2018;8:6940-6953. doi:10.1039/C7RA12775H

24. Kumar V, Bhatt PC, Rahman M, et al. Fabrication, optimization, and characterization of umbelliferone $\beta$-D-galactopyranoside-loaded PLGA nanoparticles in treatment of hepatocellular carcinoma: in vitro and in vivo studies. Int $J$ Nanomedicine. 2017;12: 6747-6758. doi:10.2147/IJN.S136629

25. Gayathri R, Priya DKD, Gunassekaran G, Sakthisekaran D. Ursolic acid attenuates oxidative stress-mediated hepatocellular carcinoma induction by diethylnitrosamine in male Wistar rats. Asian Pac J Cancer Prev. 2009;10:933-938.

26. Su XY, Zhao JQ, Li N, Kumar M, Yang A, Mei O. Chemoprotective effects of resveratrol against diethylnitrosamine induced hepatocellular carcinoma in Wistar rats. Int $J$ Pharmacol. 2019;15:549-559. doi:10.3923/ijp.2019.549.559

27. Tekkes MS, Bas C, Olgac V, Dog S, Uysal M. Effects of carnosine, taurine, and betaine pretreatments on diethylnitrosamine-induced oxidative stress and tissue injury in rat liver. Toxicol Industr Health. 2014;32(8):1405-1413.

28. Duan X, Pan Q, Yan S, Ding W, Fan J, Qiao L. High-saturate-fat diet delays initiation of diethylnitrosamine-induced hepatocellular carcinoma. BMC Gastroenterol. 2014;14:1-10.

29. Lu X, He S, Ren M, Wang Y, Zhang Y, Liu E. Chemopreventive effect of saikosaponin-d on diethylnitrosamine-induced hepatocarcinogenesis: involvement of CCAAT/enhancer binding protein $\beta$ and cyclooxygenase-2. Mol Med Rep. 2012;5:637-644. 
30. Thangavel P, Vaiyapuri M. Antiproliferative and apoptotic effects of naringin on diethylnitrosamine induced hepatocellular carcinoma in rats. Biomed Aging Pathol. 2013;3:59-64. doi:10.1016/j.biomag.2013.01.006

31. Xiao BI, Cui LI, Ma DJ, Liu SP, Zhang XU. Endoplasmic reticulum stress in diethylnitrosamine - induced rat liver cancer. Oncology Lett. 2014;7:23-27.

32. Shen T, Khor SC, Zhou F, et al. Chemoprevention by lipid-soluble tea polyphenols in diethylnitrosamine/phenobarbital-induced hepatic pre-cancerous lesions. Anticancer Res. 2014;34:683-694.

33. Kumar V, Bhatt PC, Rahman M, Al-Abbasi FA, Anwar F, Verma A. Umbelliferon- $\alpha$-D-glucopyranosyl-(2I $\rightarrow$ III)- $\alpha$-Dglucopyranoside ameliorates Diethylnitrosamine induced precancerous lesion development in liver via regulation of inflammation, hyperproliferation and antioxidant at pre-clinical stage. Biomed Pharmacother. 2017;94:834-842. doi:10.1016/j.biopha.2017.07.047

34. Kalaiselvan A, Gokulakrishnan K, Anand T, Akhilesh U, Velavan S. Preventive effect of shorea robusta bark extract against diethylnitrosamine -induced hepatocellular carcinoma in rats. Int Res $J$ Medical Sci. 2013;1:2-9.

35. Horiguchi N, Takayama H, Toyoda M, Otsuka T, Fukusato T. Hepatocyte growth factor promotes hepatocarcinogenesis through c-Met autocrine activation and enhanced angiogenesis in transgenic mice treated with diethylnitrosamine. Oncogene. 2002;21:1791-1799. doi:10.1038/sj. onc. 1205248

36. Anoopraj R, Hemalatha S, Balachandran C. A preliminary study on serum liver function indices of Diethylnitrosamine induced hepatocarcinogenesis and chemoprotective potential of Eclipta alba in male Wistar rats. Glob Health. 2014;7:439-442.

37. Rahman M, Al-Ghamdi SA, Alharbi KS, et al. Ganoderic acid loaded nano-lipidic carriers improvise treatment of hepatocellular carcinoma. Drug Deliv. 2019;26:782-793. doi:10.1080/10717544.2019.1606865

38. Chen GUO, Dai Z, Liang R, Xiao S. Characterization of diethylnitrosamine-induced liver carcinogenesis in Syrian golden hamsters. Exp Ther Med. 2012;7:285-292.

39. Gupta C, Tripathi DN, Vikram A, Ramarao P, Jena GB. Quercetin inhibits diethylnitrosamine-induced hepatic preneoplastic lesions in rats. Nutr Cancer. 2011;63:234-241. doi:10.1080/01635581.2011.523806

40. Zhang X, Yu H, Xiong Y, Ma S, Zhao L, She S. Resveratrol down-regulates myosin light chain kinase, induces apoptosis and inhibits diethylnitrosamine-induced liver tumorigenesis in rats. Int J Mol Sci. 2013;14:1940-1951.

41. Ghosh D, Choudhury ST, Ghosh S, et al. Nanocapsulated curcumin: oral chemopreventive formulation against diethylnitrosamine induced hepatocellular carcinoma in rat. Chem Biol Interact. 2012;19 5:206-214. doi:10.1016/j.cbi.2011.12.004
42. Jayakumar S, Madankumar A, Asokkumar S, et al. Potential preventive effect of carvacrol against diethylnitrosamine-induced hepatocellular carcinoma in rats. Mol Cell Biochem. 2012;360:51-60. doi:10.1007/s11010-011-1043-7

43. Chen B, Ning M, Yang G. Effect of paeonol on antioxidant and immune regulatory activity in hepatocellular carcinoma rats. Molecules. 2012;17:4672-4683. doi:10.3390/molecules 17044672

44. Afzal M, Kazmi I, Khan R, et al. Thiamine potentiates chemoprotective effects of ibuprofen in DEN induced hepatic cancer via alteration of oxidative stress and inflammatory mechanism. Arch Biochem Biophys. 2017;623-624:58-63. doi:10.1016/j.abb.2017.05.006

45. Bishayee A, Petit DM, Samtani K. Angioprevention is implicated in resveratrol chemoprevention of experimental hepatocarcinogenesis. $J$ Carcinogen Mutagen. 2010;01. doi:10.4172/2157-2518.1000102

46. Marnewick JL, van der Westhuizen FH, Joubert E, Swanevelder S, Swart P, Gelderblom WCA. Chemoprotective properties of rooibos (Aspalathus linearis), honeybush (Cyclopia intermedia) herbal and green and black (Camellia sinensis) teas against cancer promotion induced by fumonisin B1 in rat liver. Food Chem Toxicol. 2009;47:220-229. doi:10.1016/j.fct.2008.11.004

47. Abdel MT, El Asmar MF, Atta HM, et al. Efficacy of mesenchymal stem cells in suppression of hepatocarcinorigenesis in rats: possible role of Wnt signaling. J Exp Clin Cancer Res. 2011;30:49. doi:10.1186/1756-9966-30-49

48. Fang M, Dewaele S, Zhao Y, et al. Serum N-glycome biomarker for monitoring development of DENA-induced hepatocellular carcinoma in rat. Mol Cancer. 2010;9:1-15.

49. Sayed-Ahmed MM, Aleisa AM, Al-Rejaie SS, et al. Thymoquinone attenuates diethylnitrosamine induction of hepatic carcinogenesis through antioxidant signaling. Oxid Med Cell Longev. 2010;3:254-261. doi:10.4161/oxim.3.4.12714

50. Bishayee A, Barnes KF, Bhatia D, et al. Resveratrol suppresses oxidative stress and inflammatory response in diethylnitrosamine-initiated rat hepatocarcinogenesis resveratrol suppresses oxidative stress and inflammatory response in diethylnitrosamine-initiated rat hepatocarcinogenesis. Cancer Prev Res. 2010;3(6):753-763.

51. Abdel-hamid NM, Ramadan MF, Amgad SW. Glycoregulatory enzymes as early diagnostic markers during premalignant stage in hepatocellular carcinoma. Am J Cancer Prev. 2013;1:14-19.

52. Dai Z, Wu W, Kang H, et al. Protective effects of Scutellaria barbata against rat liver tumorigenesis. Asian Pac $J$ Cancer Prev. 2013;14:261-265.
Journal of Inflammation Research

\section{Publish your work in this journal}

The Journal of Inflammation Research is an international, peerreviewed open-access journal that welcomes laboratory and clinical findings on the molecular basis, cell biology and pharmacology of inflammation including original research, reviews, symposium reports, hypothesis formation and commentaries on: acute/chronic inflammation; mediators of inflammation; cellular processes; molecular mechanisms; pharmacology and novel anti-inflammatory drugs; clinical conditions involving inflammation. The manuscript management system is completely online and includes a very quick and fair peerreview system. Visit http://www.dovepress.com/testimonials.php to read real quotes from published authors. 